\title{
0 conceito de bloco no poder e o estudo das relações internacionais
}

\author{
Oswaldo E. do Amaral ${ }^{*}$
}

\section{Resumo}

Este artigo tem o propósito de contribuir para o debate teórico sobre o estudo das relações internacionais a partir de uma perspectiva marxista. Partindo da teoria política poulantziana, buscamos mostrar como o conceito de bloco no poder pode abrir novas possibilidades de análise e pesquisa sobre os fenômenos internacionais. Para isso, realizamos uma crítica a um dos pilares teóricos do estudo das relações internacionais, o realismo, e discutimos de que forma a interpretação da política externa como uma disputa política entre interesses contraditórios pode mostrar-se especialmente frutífera para a compreensão da ação internacional dos Estados.

PalaVras-ChaVe: RelaÇões internaCionais; MARXismo; ReAlismo; BURgueSia

\section{Abstract}

This article aims to contribute, from a marxist point of view, with the theoretical debate about the study of international relations. From a Poulantzian perspective, we want to discuss how the 'power bloc' concept can open new possibilities of analysis and research in this field. In the article, we criticize one of the most important theories

* Doutorando em Ciência Política no Instituto de Filosofia e Ciências Humanas (IFCH) da Universidade Estadual de Campinas (Unicamp) e professor de Relações Internacionais Contemporâneas no Centro Universitário Belas Artes de São Paulo.

cadernos cemarx, no $4-2007 \quad 125$ 
of international relations, the realism, and try to argue that the interpretation of a foreign policy as a political struggle between contradictory interests can be extremely useful to understand states' action in the international arena.

KEYWORDS: INTERNATIONAL RELATIONS; MARXISM; REALISM; BOURGEOISIE

\section{INTRODUÇão}

O objetivo deste artigo é apontar alguns aspectos em que a teoria política poulantziana pode contribuir para o desenvolvimento do estudo das relações internacionais. Obviamente, esta é uma empreitada que ultrapassa, em muito, os limites deste trabalho, dada a variedade de teorias que tratam das relações internacionais e a complexidade e abrangência da teoria política poulantziana. Acreditamos, porém, que o encontro entre o marxismo estrutural de Poulantzas e o estudo das relações internacionais possa abrir inúmeras possibilidades de análise e descortinar novos caminhos de pesquisa. Este encontro talvez ganhe em importância se observarmos, seguindo as pistas indicadas por Fred Halliday, que o marxismo não ocupa nas Relações Internacionais o mesmo espaço que em outras áreas das Ciências Sociais. Como causas para esta timidez teórica, Halliday (1999: 64) aponta a prevalência do economicismo no campo do marxismo, que acabou por "enfraquecer qualquer tentativa de explicar as questões políticas, ideológicas e de segurança” no âmbito internacional, e o fato da disciplina de Relações Internacionais, desde o seu surgimento, na década de 20 do século passado, ter se desenvolvido especialmente em escolas inglesas e norte-americanas tradicionalmente refratárias ao pensamento marxista. Dificuldades institucionais e teóricas à parte, Halliday é muito claro ao afirmar que o materialismo histórico pode apresentar uma alternativa teórica e empírica fundamental para se trabalhar dentro da disciplina de Relações Internacionais'.

Neste artigo, buscaremos realizar, de forma sucinta, uma crítica à teoria realista das relações internacionais a partir da teoria política poulantziana e discutir como o conceito de bloco no poder pode ser especialmente frutífero teoricamente para a análise da ação internacional dos Estados. A crítica ao realismo justifica-se pelo fato deste, há

1 Sobre isto ver a interpretação de Halliday (1999) a respeito da Guerra Fria e o conceito de conflito intersistêmico.

1260 conceito de bloco no poder e 0 estudo das relações internacionais 
pelo menos 60 anos, dominar o debate teórico e ser um dos pilares analíticos das relações internacionais. Já com relação ao conceito de bloco no poder é necessário dizer que, dentro da construção teórica a respeito do Estado capitalista feita por Poulantzas, muitos outros conceitos poderiam ser escolhidos para serem desenvolvidos. A decisão pelo conceito de bloco no poder deve-se, assim, aos seguintes fatores: a) por se mostrar fundamental para entendermos as ações do Estado, como veremos adiante; b) pelo fato do próprio Poulantzas (1976: 30-31) nos apontar a possibilidade de analisarmos as ações internacionais de um determinado Estado a partir das contradições decorrentes da configuração do bloco no poder. Antes de prosseguirmos com uma breve exposição sobre os principais elementos da teoria realista, convém mencionar que utilizaremos aqui as formulações teóricas desenvolvidas por Poulantzas em Poder político e classes sociais (1986) e em A crise das ditaduras: Portugal, Grécia, Espanha (1976), bem como outros trabalhos que discutem e aplicam a teoria poulantziana na explicação de fenômenos concretos, como "A burguesia no governo Lula" (Boito Jr., 2005).

\section{A teoria Realista ${ }^{2}$}

Dominante entre analistas e acadêmicos das relações internacionais, bem como entre tomadores de decisões e formuladores de política externa, a teoria realista apresenta uma grande diversidade de caminhos e interpretações. Nada mais natural para uma corrente teórica sujeita a intenso debate e críticas por pelo menos 60 anos. Realismo clássico, neo-realismo, realismo neoclássico e neo-realismo ofensivo são classificações utilizadas para designar algumas das variações da matriz realista. Não cabe aqui nos aventurarmos por todas as elaborações teóricas realistas, mas sim partirmos de alguns conceitos e idéias comuns a todas elas.

No intuito de apresentar as Relações Internacionais como uma disciplina autônoma e legitimar o seu estudo separado das outras ciências sociais, os autores realistas foram buscar inspiração teórica em pensadores como Maquiavel e Hobbes. Do primeiro, extraíram a preocupação com a verità effetuale, afirmando a necessidade

2 Utilizamos para esta breve caracterização da teoria realista das relações internacionais as seguintes obras: Teoria das Relações Internacionais (Braillard, 1990); Teoria das relações internacionais: correntes e debates (Nogueira \& Messari, 2005); The Penguin Dictionary of International Relations (Evans \& Newnham, 1998).

cadernos cemarx, n-0 4-2007 127 
de se enxergar a realidade internacional como ela de fato é e não como deveria ser, opondo-se assim à corrente idealista, outro pilar teórico das relações internacionais. Como bem sintetiza Philipe Braillard (1990: 113-114),

todos os autores que podemos classificar sob a etiqueta de "realistas" (...) têm em comum uma concepção da política internacional fundada na vontade de considerar o homem e as relações sociais - e neste caso, mais particularmente, as relações políticas - tal como elas são e não como eles gostariam que elas fossem.

De Hobbes, apropriaram-se do conceito de estado de natureza, desenvolvendo a idéia de que o sistema internacional, pela ausência de um soberano que garanta a paz e a segurança, viveria em permanente 'anarquia'. Até que ponto a leitura realista de autores clássicos como Hobbes e Maquiavel foi enviesada para justificar seus propósitos teóricos é tema de intensa discussão e não nos cabe neste momento enveredarmos por este caminho. O que nos interessa aqui é o fato de que as idéias expostas acima indubitavelmente estão presentes em todo o pensamento realista.

Após esta breve introdução a respeito das alegadas origens do pensamento realista, observaremos agora alguns de seus principais elementos teóricos. O primeiro deles é a grande ênfase no sistema internacional. Ou seja, para os realistas, o que acontece dentro dos Estados não interessa na análise das relações internacionais. Como muito bem colocam Nogueira e Messari (2005: 24), "o que chama a atenção dos realistas são os fatores internacionais, o que se traduz, por exemplo, em enfatizar a distribuição do poder entre os diferentes atores internacionais [Estados] mais do que os determinantes domésticos do poder".

Essa ênfase está diretamente vinculada à forma com que os realistas tratam o Estado, sendo este o segundo elemento que gostaríamos de destacar. Para os realistas, o Estado é o ator central das relações internacionais. Este ator, por sua vez, é unitário e racional, agindo sempre de forma homogênea na defesa do 'interesse nacional'. A forma com que o 'interesse nacional' é determinado não preocupa os realistas, embora ele contenha um elemento mínimo que é, em última instância, a sobrevivência do Estado. Isto nos leva a concluir que, segundo o realismo, todos os Estados agem de forma semelhante na esfera internacional, buscando realizar seu 'interesse nacional' com o menor custo possível, o que justifica a preocupação exclusiva com a atuação estatal na esfera internacional.

1280 conceito de bloco no poder e o estudo das relações internacionais 
Conforme avaliam os realistas, em um mundo 'anárquico', definido pela ausência de uma autoridade superior que regule a relação entre os Estados, $o$ 'interesse nacional' - mesmo que entendido apenas como a sobrevivência do Estado - só pode ser realizado a partir do acúmulo de poder. Partindo desta elaboração teórica, o objetivo da política externa de qualquer país está diretamente ligado à aquisição de poder, o que faz com que o realismo qualifique a política internacional como 'a luta pelo poder'. Não há entre os realistas uma definição clara de poder na esfera internacional, embora todos concordem com a sua centralidade para o estudo das relações internacionais. É possível, porém, verificarmos duas linhas interpretativas com relação a este importante aspecto teórico: a) o poder é "entendido como a soma das capacidades do Estado em termos políticos, militares, econômicos e tecnológicos" (Nogueira \& Messari, 2005: 28); b) o poder é tratado como a capacidade de um Estado de influenciar o comportamento do sistema internacional ou de resistir a imposições deste.

Expostos alguns dos elementos básicos da teoria realista das relações internacionais, devemos mencionar que a força desta teoria reside justamente no fato dela fornecer uma explicação abrangente sobre o comportamento dos Estados na esfera internacional, tornando-se assim, segundo a interpretação de Braillard (1990: 113), uma teoria geral das relações internacionais. Vejamos o que diz o autor a este respeito:

por teoria geral das relações internacionais entendemos uma teoria que procura, a partir de uma visão global, esclarecer estas relações no seu conjunto, por oposição a uma teoria parcial que se limita a um aspecto destas relações, a um tipo de processo que elas manifestam, que procura explicar em detalhe certos tipos precisos de comportamento.

O realismo, como dissemos, foi objeto das mais variadas críticas pelas mais diferentes correntes teóricas das Relações Internacionais e das Ciências Sociais. Seus pressupostos teóricos foram questionados, bem como seu desenvolvimento metodológico. Seguindo com a proposta deste trabalho, tentaremos realizar uma crítica a alguns elementos da teoria realista expostos acima a partir da teoria política poulantziana, o que nos servirá de base para a posterior discussão a respeito da contribuição que o conceito de bloco no poder pode trazer para o estudo das relações internacionais. 


\section{UMA BREVE CRÍTICA AO REALISMO}

A partir da teoria política desenvolvida por Poulantzas, inúmeras podem ser as críticas ao realismo nas relações internacionais. Nos concentraremos aqui em alguns aspectos que consideramos importantes para o ulterior desenvolvimento de nosso artigo. Podemos iniciar afirmando que, do ponto de vista do trabalho desenvolvido por Poulantzas em Poder político e classes sociais (1986), o realismo nos explica muito pouca coisa. Mesmo que voltada para o âmbito internacional, não seria muito difícil inscrever a teoria realista, especialmente na sua forma como trata o Estado, no quadro da ideologia burguesa, pois não há dúvida que ela preenche o requisito de funcionar como uma 'máscara', contribuindo para o ocultamento do nível econômico sempre determinante e do nível que assume o papel dominante (Poulantzas, 1986: 205).

Ao qualificar o Estado como um agente racional que busca sempre o interesse nacional', a teoria realista trata, mesmo que de maneira indireta, o Estado enquanto encarnação da vontade geral frente aos indivíduos iguais e isolados, contribuindo assim para que os agentes da produção não percebam, na sua luta econômica, as suas relações de classe (Poulantzas, 1986: 126-133). Esta característica da teoria realista torna-se ainda mais evidente quando esta enfatiza o sistema internacional e se recusa a observar os fatores internos que determinam o 'interesse nacional' defendido pelo Estado, encobrindo definitivamente o seu caráter de classe.

Partindo da perspectiva poulantziana, é absolutamente impossível, como pretende o realismo, tratar qualquer ação do Estado sem levar em consideração o fato deste, em uma formação social dominada pelo modo de produção capitalista, "organizar a dominação de classe da burguesia ao mesmo tempo em que organiza a hegemonia de uma determinada fração burguesa" (Boito Jr., 2005: 55).

\section{O CONCEITO DE BLOCO NO PODER E AS RELAÇÕES INTERNACIONAIS}

O último item deste artigo volta-se para o conceito de bloco no poder e a sua capacidade de auxiliar no desvelamento das relações internacionais. Comecemos por um breve esclarecimento teórico. Para Poulantzas (1986: 293), em decorrência da unidade própria do poder político e da autonomia relativa do Estado, características estas específicas do Estado em uma formação social dominada pelo modo de produção capitalista, "o bloco no poder constitui uma unidade contraditória das

130 conceito de bloco no poder e 0 estudo das relações internacionais 
classes ou frações dominantes, unidade dominada pela classe ou fração hegemônica". Esta unidade se dá porque a toda a burguesia interessa a manutenção das condições de perpetuação do capitalismo, condições estas que o Estado garante assegurando a propriedade privada dos meios de produção e a reprodução da força de trabalho como mercadoria. No entanto, Poulantzas qualifica a unidade como contraditória pelo fato desta não estar livre de cisões. Segundo a definição de Boito Jr. (2005: 54-55),

trata-se de uma unidade contraditória porque os capitalistas, para além da sua unidade geral, estão distribuídos, de acordo com a posição particular que ocupam no processo de produção num momento e num país determinados, em setores econômicos diferenciados que poderão se constituir em frações de classe perseguindo interesses específicos - alguns elementos potenciais de divisão da burguesia em frações de classe são: as fases do ciclo de reprodução do capital (capital dinheiro, capital produtivo, capital comercial), o poderio econômico das empresas (grande capital, médio capital, capital monopolista), as relações variadas das empresas com a economia internacional (origem do capital, destino da produção para o mercado interno ou para a exportação).

Como bem advertem Farias (2004: 65) e Boito Jr. (2005), a constituição de frações de classe e o seu eventual alinhamento devem também levar em consideração as especificidades de uma determinada formação social e a existência de modos de produção não-dominantes, assim como as políticas governamentais adotadas pelo Estado.

Seguindo na exposição a respeito do conceito de bloco no poder, devemos destacar que Poulantzas (1986: 296) enfatiza o papel do Estado enquanto constituinte do "fator de unidade política do bloco no poder sob a égide da classe ou fração hegemônica”. Ao fazer esta afirmação, Poulantzas busca reforçar a posição teórica de que o Estado não é um simples utensílio nas mãos da burguesia, mas sim o responsável direto pela organização da dominação de classe da burguesia e, mais especificamente, da hegemonia de uma determinada fração burguesa (Boito Jr., 2005: 55). Desta maneira, podemos concluir que o Estado capitalista atua de acordo com os interesses gerais da burguesia e, dentro destes, privilegia os interesses determinados de uma fração específica da burguesia. Segundo Boito Jr. (2005: 55), “o conceito de bloco no poder opera, então, com dois aspectos básicos: de um lado, a unidade contraditória da burguesia e, de outro, o papel ativo que o Estado desempenha na organização da dominação de classe da burguesia e da hegemonia de uma de suas frações”.

cadernos cemarx, no $4-2007 \quad 131$ 
Para que fique ainda mais clara a conceituação de bloco no poder, vejamos como Boito Jr. (2002; 2005) a utiliza em uma análise concreta. Segundo o autor, no Brasil, a política de Estado, durante o período de prevalência do modelo capitalista neoliberal, atuou hierarquizando os interesses da burguesia, configurando, assim, um bloco no poder neoliberal. Desenvolvendo a análise, Boito Jr. desagrega a política neoliberal em três elementos - ou partes: a) desregulamentação do mercado de trabalho e redução dos direitos sociais; b) privatizações; c) abertura comercial e desregulamentação financeira. O primeiro deles é o que o autor chama de círculo de ferro da unidade burguesa, pois atende indistintamente a todos os capitalistas, garantindo o apoio conjunto da burguesia ao modelo neoliberal. Já a política de privatizações tem um efeito mais restrito, atendendo aos interesses do grande capital (estrangeiro, nacional, industrial e financeiro), excluindo assim o pequeno e o médio capital. Por último, a abertura comercial e a desregulamentação financeira contemplam apenas os interesses do grande capital financeiro nacional e internacional, deixando de lado o setor industrial. A partir destas considerações, é possível concluir que

todos os aspectos da política neoliberal - a desregulamentação, a privatização, a abertura comercial - atendem integralmente aos interesses de uma única fração da burguesia: o grande capital financeiro. As demais frações integrantes do bloco no poder (...) têm conflitos, maiores ou menores, com um ou mais desses elementos. $\mathrm{O}$ resultado prático da correspondência objetiva entre o modelo capitalista neoliberal e os interesses financeiros é a taxa de lucro superior do sistema financeiro frente à taxa de lucro do setor produtivo (Boito Jr., 2005: 60-61).

Conforme a exposição de Boito Jr., é possível enquadrarmos o grande capital financeiro como a fração de classe hegemônica do bloco no poder no período de vigência do neoliberalismo no Brasil. No entanto, essa hegemonia política não ocorre sem resistência por parte de outras frações, estabelecendo-se assim uma relação de unidade e de luta dentro do bloco no poder que se evidencia dentro do Estado. Para que fique mais clara essa relação conflituosa, vejamos o que afirma Poulantzas (1976: 65) em uma passagem bastante esclarecedora:

assim como o 'capital' já contém em si a contradição capital/trabalho assalariado, as contradições de classe atravessam sempre, de ponta a ponta, o Estado, porque

1320 conceito de bloco no poder e o estudo das relações internacionais 
pela sua natureza de Estado de classe, reproduz no seu próprio seio as contradições de classe, o que significa claramente que estas se exprimem sempre e de forma específica como contradições internas do Estado, que jamais é, nem pode ser, um bloco monolítico sem fissuras.

Após esta breve introdução teórica a respeito do conceito de bloco no poder, podemos agora nos concentrar na sua articulação com o estudo das relações internacionais. Como mencionamos acima, seguindo algumas pistas fornecidas por Poulantzas em A crise das ditaduras: Portugal, Grécia, Espanha (1976) é possível entender as ações dos Estados no âmbito internacional segundo o seu papel de "fator de unidade política do bloco no poder sob a égide da classe ou fração hegemônica" (Poulantzas, 1986: 296). Vejamos o que diz o autor a respeito da ação internacional dos EUA e suas respectivas variações:

tal pluralidade de táticas [internacionais] dos Estados Unidos não se deve simplesmente a uma atitude constante de sua parte: prende-se igualmente às próprias contradições do capital americano. (...) O capital americano internacionalizado e as grandes firmas multinacionais americanas apresentam contradições importantes com as frações deste capital baseadas na acumulação e expansão, principalmente dentro do país; daí uma oscilação da política americana entre um expansionismo agressivo, que prevalece constantemente, e uma tendência permanente para uma forma de isolacionismo (Poulantzas, 1976: 30-31).

O que Poulantzas parece indicar é justamente o fato de que a política externa norte-americana expressa determinadas situações específicas do bloco no poder. Visão semelhante tem Boito Jr. (2005: 62) ao fazer uma breve análise da política externa brasileira no governo Lula. Para o autor, uma nova situação do bloco no poder no Brasil, em que a hegemonia do grande capital financeiro (nacional e internacional) convive com a "ascensão política da grande burguesia interna industrial e agrária voltada para o comércio de exportação" é claramente expressada na política externa do governo petista. Segundo Boito Jr. (2005: 70),

o presidente Lula diz estar lutando por uma nova 'geografia comercial' e é aqui que reside o segredo da vinculação de sua política externa com a sua política econô-

cadernos cemarx, n-0 4-2007 133 
mica. A política externa é, ao mesmo tempo, dependente (frente ao imperialismo) e conquistadora (frente às pequenas e médias economias da periferia). De um lado, atendem-se às exigências do imperialismo, como o envio de tropas ao Haiti, e se reafirma a posição subalterna do capitalismo brasileiro na divisão internacional do trabalho, mas, de outro lado, o governo quer ocupar de fato o lugar que cabe ao capitalismo brasileiro nos mercados agrícola, de recursos naturais e produtos industriais de baixa tecnologia, mesmo que para tanto o capitalismo brasileiro deva expandir-se às custas das demais burguesias latino-americanas e mesmo que gere tensões localizadas com alguns países dominantes.

Com as duas referências feitas acima, buscamos chamar a atenção para a importância da configuração do bloco no poder para a análise das relações internacionais, deixando claro que um importante aspecto da teoria política poulantziana pode auxiliar na compreensão das ações estatais no plano internacional. Mais do que isso, parece-nos igualmente importante que as análises poulantzianas a respeito do bloco no poder levem também em consideração a ação internacional dos Estados, pois, como pudemos ver, estas ações exprimem determinadas contradições no bloco no poder e podem, eventualmente, repercutir na sua composição, alterando-a.

Outro ponto que gostaríamos de destacar é a possibilidade de desenvolvimento de uma abordagem marxista das relações internacionais baseada na teoria política poulantziana. Interpretar a ação estatal no plano internacional entendendo o Estado como "fator de unidade política do bloco no poder sob a égide da classe ou fração hegemônica" (Poulantzas, 1986: 296) nos parece ser um bom ponto de partida, especialmente se levarmos em consideração que o paradigma dominante na área, o realismo, interpreta o Estado como uma 'caixa-preta' que defende indistintamente o 'interesse nacional'. Partindo do conceito de bloco no poder, é possível interpretarmos a política externa - assim como a econômica - como uma disputa política entre interesses contraditórios (Boito Jr., 2005: 55). Esta conclusão tem importantes implicações para o estudo das relações internacionais, pois desqualifica completamente um dos mais importantes conceitos do realismo, além de fornecer uma explicação para as mudanças nos rumos da política externa de um determinado Estado. Esta abordagem abre-nos ainda a possibilidade de entendermos de forma mais nítida as relações entre o interno e o internacional e as eventuais relações - e influências - entre os blocos no poder nos mais diferentes Estados.

1340 conceito de bloco no poder e o estudo das relações internacionais 
BIBLIOGRAFIA

BOITO JR., Armando. "Neoliberalismo e relações de classe no Brasil”. In: Idéias, Campinas: IFCH/Unicamp, n.9, 2002

“A burguesia no governo Lula”. In: Crítica Marxista, Rio de Janeiro:

Revan, n.21, 2005

BRAILLARD, Phillippe. Teoria das Relações Internacionais. Lisboa: Fundação Calouste Gulbenkian, 1990

CASTRO, Flávio Antônio de. "O Estado do modo de produção capitalista em Poulantzas e Miliband: conflito ou complemento?”. In: Cadernos Cemarx, Campinas: Cemarx/IFCH/Unicamp, n.1, 2004

EVANS, Graham \& NEWNHAM, Jeffrey. The Penguin Dictionary of International Relations. London: Penguin, 1998

FARIAS, Francisco P. de. (2004). “Sobre a questão das frações de classe dominante”. In Cadernos Cemarx, n.1. Campinas: Cemarx/IFCH/Unicamp

HALLIDAY, Fred. Repensando as relações internacionais. Porto Alegre: UFRGS, 1999

NOGUEIRA, João P. \& MESSARI, Nizar. Teoria das relações internacionais: correntes e debates. Rio de Janeiro: Elsevier, 2005

POULANTZAS, Nicos. A crise das ditaduras: Portugal, Grécia, Espanha. Rio de Janeiro: Paz e Terra, 1976

Poder político e classes sociais. São Paulo: Martins Fontes, 1986 